\title{
An Ultimate Method for Cleft Nasal Deformity Correction at Primary Lip Surgery: Innovative Concepts and Review
}

\author{
Badr MI Abdulrauf, MD, FRCSC \\ Plastic and Reconstructive Surgery, Department of Surgery, King Faisal Specialist Hospital and Research Center, Saudi \\ Arabia
}

\begin{abstract}
The Nasal deformity in individuals with clefts has been an area of controversies, challenges and diversity of techniques. The aesthetic outcomes have barely been acceptable or below expectations most of the time and globally.

Method: We believe on the theory of a "collapsing pyramid" for the Nasal cartilaginous framework in clefts. Hence, we came up with a true suspension technique. The entire cartilaginous structure is lifted from infra tip region, with a loop suture and being secured onto the periosteum overlying nasal bone in a cantilever fashion.

This method is being used at the primary stage in both Unilateral and Bilateral Nasal-cleft lip deformities. Major works and milestones relevant to this topic by renowned authors are reviewed and discussed.

Results: The technique was first applied over 10-years-ago. Nine children whose parents consented to the developing technique have been presented, with follow ups ranging from few months to years. Technical descriptions and illustrative drawings made by the author are portrayed.

None of the cases has had preoperative orthopedic procedures, moldings or even postoperative nostril splints. The aesthetic outcome was adequately striking and optimum, none of the cases requested a secondary correction to the nose.

Conclusion: The new nasal suspension technique is an innovative concept, which can be used in conjunction to an appropriate lip repair method as per the surgeon's preference. The main drawback would be the need for a learning curve. Overall, we believe this is an ultimate solution for the severe nasal deformity, since it truly suspends the nose in a cantilever fashion, securing it to a stable structure, the periosteum of the nasion.
\end{abstract}

\section{Keywords}

Cleft, Lip, Nasal, Deformity, Unilateral, Bilateral, Technique, Correction, Rhinoplasty

\section{Abbreviations}

UCLND: Unilateral Cleft Lip Nasal Deformity; BCLND: Bilateral Cleft Lip Nasal Deformity; NAM: Naso-alveolar molding

\section{Introduction}

Only after spending several years of cleft work, one appreciates how difficult it is to achieve good results to the nose in cleft lip patients. Earlier in one's practice we were mostly challenged about closing a large size cleft and achieving a good alignment to the lip. It was very truly stated: "Cleft lip surgery is essentially an operation to the Nose" [1].

Unilateral cleft lip nasal deformity (UCLND) has been investigated and written about far more than the Bilateral counterpart, an observation that can be easily made upon reviewing this subject [2-5]. The rationale is not barely, the solutions applied to the former can simply be applied on both sides. It is the tilt of the tripod in the Unilateral cases beginning with the infrastructure (maxilla) up to the skin and hence the asymmetry, what challenged surgeons the most [5].
The main difficulty with the Bilateral cleft lip nasal deformity (BCLND), namely short columella from mild to non-existent, was eventually addressed by Mulliken [1], the technique has been acknowledged as a major milestone, though like every other technique it also has its drawbacks.

*Corresponding author: Badr MI Abdulrauf, MD, FRCSC, Program Director, Section of Plastic and Reconstructive Surgery, Department of Surgery, King Faisal Specialist Hospital and Research Center, Jeddah, Saudi Arabia

Accepted: July 07, 2020

Published online: July 09, 2020

Citation: Abdulrauf BMI (2020) An Ultimate Method for Cleft Nasal Deformity Correction at Primary Lip Surgery: Innovative Concepts and Review. Archives Oral Maxillofac Surg 3(1):36-49 


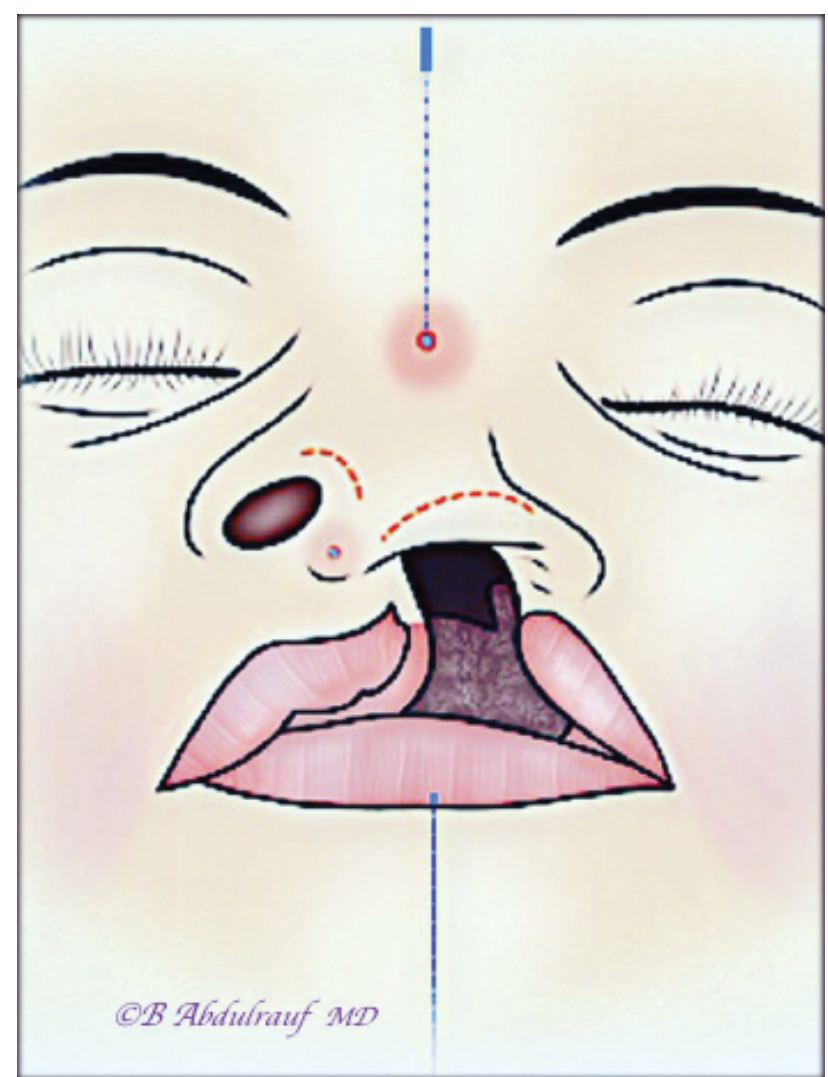

Figure 1: Incisions utilized in the semi-closed Nasal Cantilever Technique "NCT". These include bilateral rim incisions, and two $18 \mathrm{G}$ needle induced stab incisions externally, a cephalic at radix, and caudal one at the future infra-tip point. A "UCLND" example is used in this illustration. Midline is marked on the glabella, and on the lower lip as reference points for the cephalic radix opening, where the nasal tip should be aimed to be positioned at completion of the case.

We are introducing a complementary concept that combines suspension, traction of the freed and fully mobilized lower lateral cartilages, however to the nasal bone's periosteum, and in a closed manner. This is beside few well established maneuvers.

Although we first thought of this idea and applied it 10-years-ago, it is only recently we decided to report after observing convincing results by ourselves, and more importantly the parents of these children have not asked for further nasal correction unlike some other cases which have undergone preschool cleft rhinoplasty. The other factors which are common in these particular cases were: None of them had any presurgical orthopedic manipulations, NAM or postoperative nostril splints.

Nine children who were subjected to our method are presented in this paper. These were selected on basis of delayed timing of surgery and or their parents fully consented on a new innovative technique. The first two cases were involved mainly for technical demonstration purposes (Figure 2 and Figure 9).

\section{Method/Operative Technique}

The marking and operation are being done under Loupe magnification. Besides the diluted adrenaline, the nasal mucosa is also infiltrated with inject able normal saline specifically to tip, columellar area if present, and over the lower lateral cartilages. This step helps as a hydro-dissection, makes the isolation of the flimsy cartilages relatively easier.

Surgery begins with the lip incisions and dissection; the specific method is selected as per the case. Then attention is turned towards the nasal operation.

The nasal surgery is done entirely through rim incisions and two $18 \mathrm{G}$ needle induced stab incisions externally (Figure 1).

Initially the rim incisions are made. The alar cartilages are carefully dissected and fully skeletonized on both sides as a closed technique. In UCLND, the normal side dissection is limited to the dome and proximal lateral crus. Nasal skin is undermined all the way to the radix, including the triangular cartilage region. Lateral crural stael or mobilization is considered to build the deficient columella. Trans-domal, equalization sutures are placed using PDS 5.0 Next, a Cinch suture to the fibro fatty tissue using Ethibond 3.0 is placed, (holding both alae in case of BCLND or one side in case of UCLND), and secured into the premaxillary periosteum. Both the domal and cinch sutures are left untied at this point.

Two $18 \mathrm{G}$ needle induced stab mini incisions are made, one on the nasal radix and second one just caudal to future nasal tip.

A Malleable suture passer is introduced through the mini stab incision at radix, which then advanced subcutaneously in the previously undermined plane on one side of the cartilaginous framework, and brought out from the infra tip needle induced incision. A vicryl 4.0 thread is used, caught and brought out of the opening at radix. The suture passer then re-introduced for second time from the radix, this time pierces into the nasal bone periosteum, then it is driven in the contralateral side to the initial one in relation to the cartilaginous framework. It is brought out again through the infra-tip opening and the other end of thread is held and pulled back smoothly, making sure not to lose the subperiosteal plane on the nasal bone. This way, a loop is being created that is going around the infra-tip (caudal to the domes) and holding entire cartilaginous framework to the nasion. It is optional whether to catch the periosteum on the first pass or second, either way the objective is to make the final surgical knot on the nasal bone periosteum (Figure 3 and Figure 4).

Next, the cinch suture is tied, followed by the trans-domal, equalization suture(s) and then the loop suture is tied last, the knot is kept well away from the radix opening Figure 4, Figure 5, Figure 6, and Figure 11. No consideration for septal dissection or interventions is considered in this technique.

We often tend to place bolster suture(s) as a support for to the dead space usually to the alae, this reduces any minor hematomas hence helps in reducing fibrosis, these are removed in 48 hours (Figure 6 and Figure 11).

A thin Duoderm or similar dressing is taped over the nose as a splint, we believe it helps in reducing dead space as well 
Citation: Abdulrauf BMI (2020) An Ultimate Method for Cleft Nasal Deformity Correction at Primary Lip Surgery: Innovative Concepts and Review. Archives Oral Maxillofac Surg 3(1):36-49

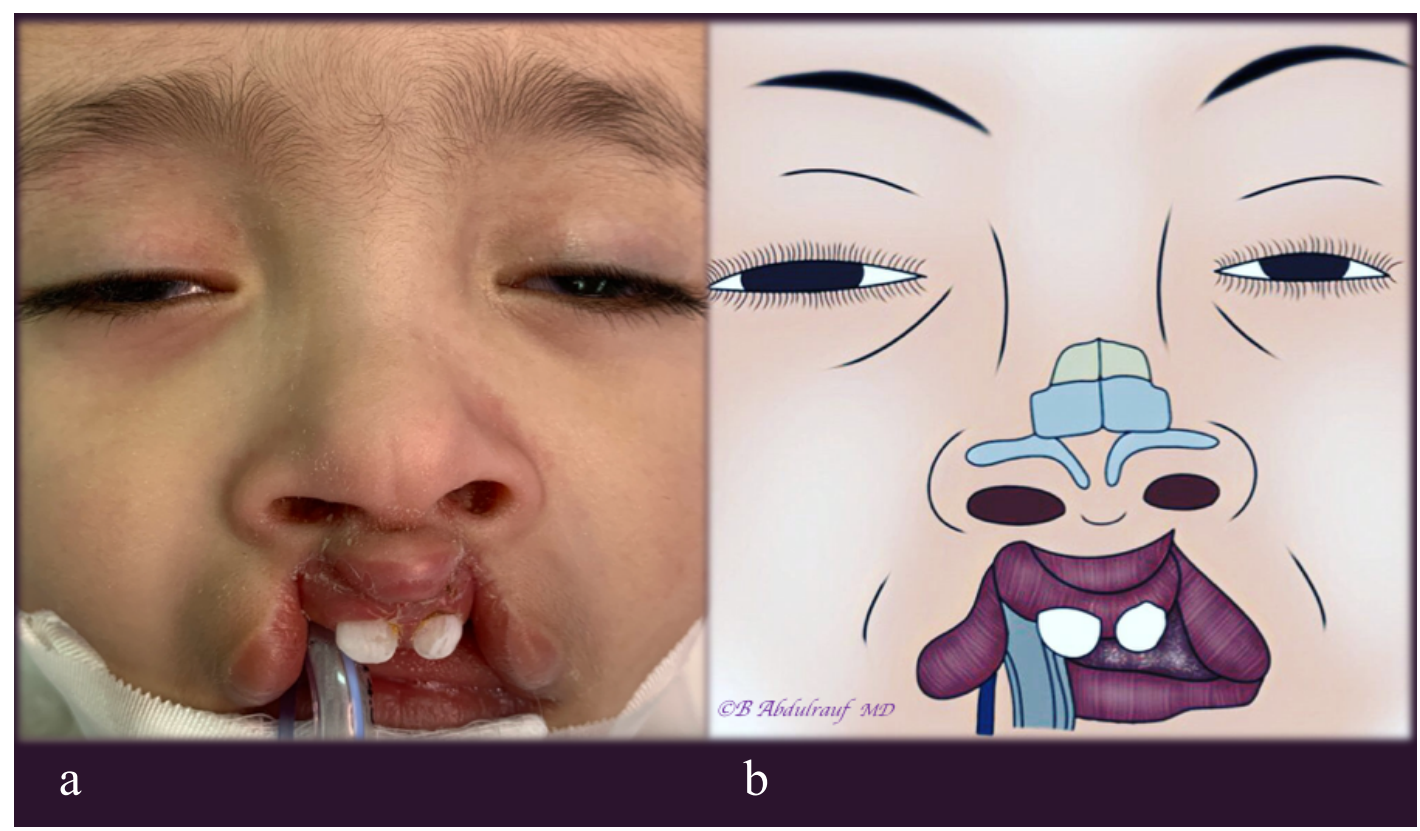

Figure 2: Case 1, BCLND, splayed lower lateral cartilages, flattened bifid tip and short columella (a), and artist's depiction of underlying anomaly (b).

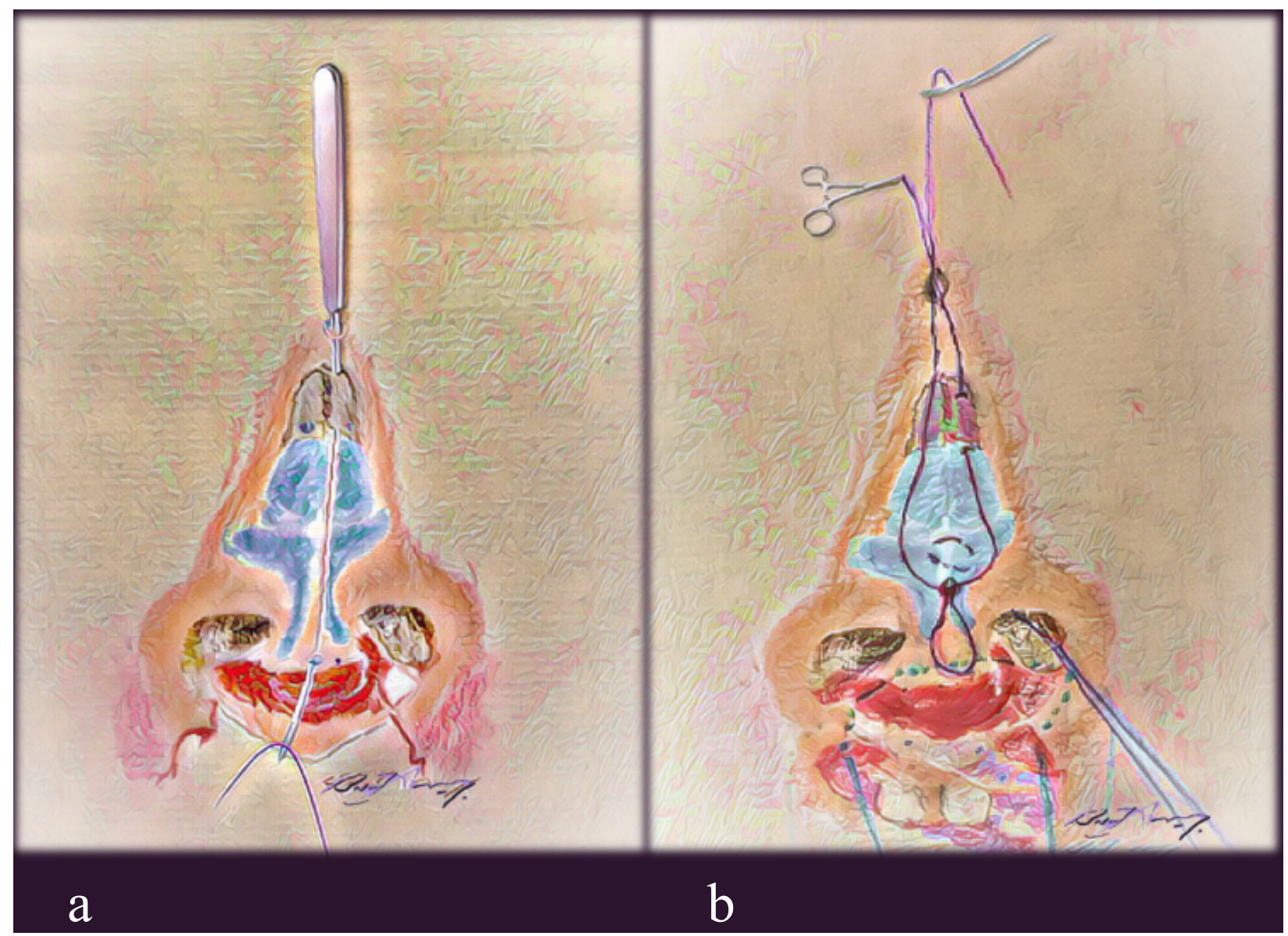

Figure 3: Author's illustration of the NCT in case of a BCLND, a malleable suture passer has been introduced from radix opening cephalically, partly embedded in the periosteum overlying nasal bone, exited from the infra-tip opening caudally. It is catching the thread (violet color) to retrieve it and pull it out at the radix (a). Then after repeating same maneuver on other side but maintaining a superficial track a loop is created. The tip trans-domal suture (blue) and cinch suture (green) are also shown; none of the 3 key sutures are tied yet (b). 


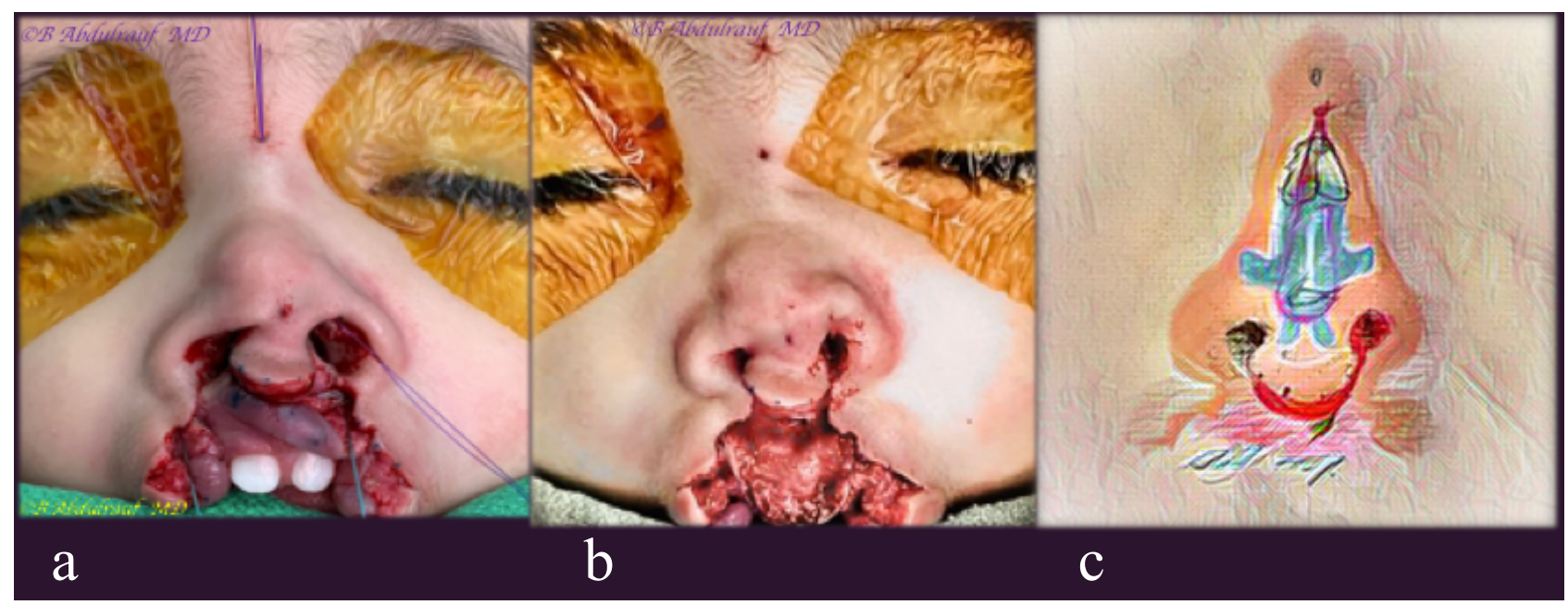

Figure 4: Case1intraoperative, all 3 main sutures been placed as per the steps shown in the previous illustration (a). The sutures have been tied beginning with the cinch, followed by trans-domal and last the loop suture was tied; The Bilateral cleft lip is still not repaired yet, but the nose has been fully addressed with the semi-closed technique (b). Author's depiction of the underlying nasal repair and role of various sutures (c).

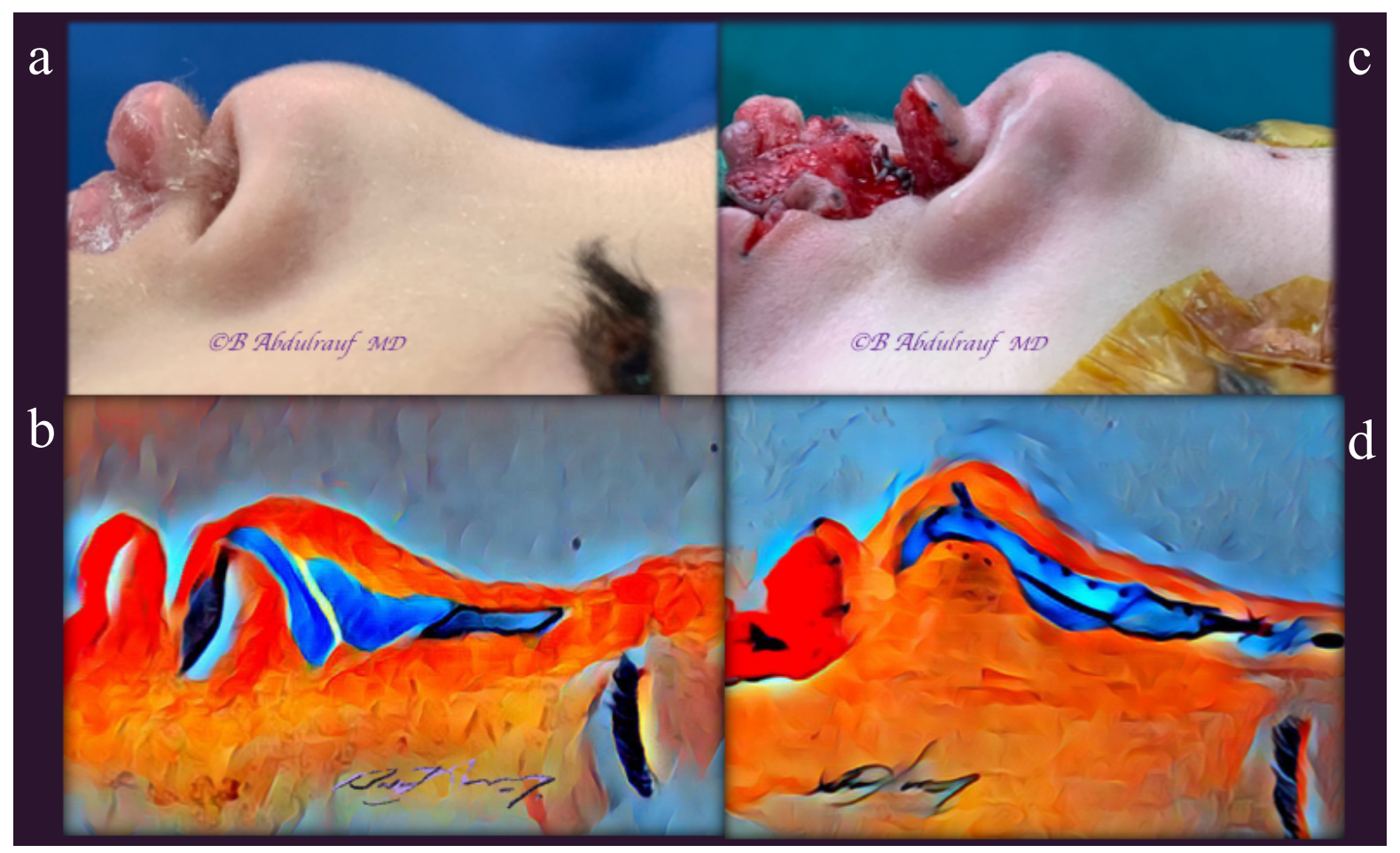

Figure 5: Case 1 profile views intraoperatively and immediately after completing Nasal correction using the NCT, the lip is still open (a, b). Author's illustration of the underlying repair in profile view, which gives best explanation how the technique suspends the entire nose from the infra-tip region, and holds it solidly with the mattress cable suture tied to the periosteum; the columella has been restored, its shape been maintained with the loop suture as a checkrein mechanism (c, d).

warning others for need for extra precautions towards the nose. Removable and protective arm splints are routinely used and advised for these children in first 3 weeks.

Over the lip repair site, topical antimicrobial ointment is used with frequent cleansing using normal saline.

\section{Results}

In total, nine patients were subjected to the Nasal suspen- sion method beside lip repair, as the only surgical intervention to the nose and lip up to their last follow up. The first two cases were recent and mostly done as demonstration with short follow up. Age at time of this primary surgery ranged from 4 months to 2-years (Table 1 ).

In terms of complications, in case 3 we encountered an issue with the alar cinch suture, a stitch granuloma. It was considered to be pulled out under conscious sedation. 
Citation: Abdulrauf BMI (2020) An Ultimate Method for Cleft Nasal Deformity Correction at Primary Lip Surgery: Innovative Concepts and Review. Archives Oral Maxillofac Surg 3(1):36-49

Table 1: The follow up result photos are taken at time frame anywhere between 3 months to 10 -years postoperatively.

\begin{tabular}{|l|l|l|l|l|}
\hline Case & Type of Cleft & Age at Surgery & Postop. Follow up Period & Figure \# \\
\hline 1 & BCLND & $14 \mathrm{M}$. & $3 \mathrm{M}$. & $\begin{array}{l}\text { Figure 2, Figure 3, Figure 4, Figure 5, Figure 6, } \\
\text { Figure 7, Figure 8 }\end{array}$ \\
\hline 2 & UCLND & & Figure 9, Figure 10, Figure 11, Figure 12 \\
\hline 3 & BCLND & $4 \mathrm{M}$. & $4 \mathrm{M}$. & Figure 13 \\
\hline 4 & BCLND & $6 \mathrm{M}$. & $1 \mathrm{Y}$. & Figure 14 \\
\hline 5 & UCLND & $8 \mathrm{M}$. & $2 \mathrm{Y}$. & Figure 15 \\
\hline 6 & UCLND & $18 \mathrm{M}$. & $6 \mathrm{Y}$. & Figure 16 \\
\hline 7 & UCLND & $11 \mathrm{M}$. & $6 \mathrm{Y}$. & Figure 17 \\
\hline 8 & UCLND & $5 \mathrm{M}$. & $10 \mathrm{Y}$. & Figure 18 \\
\hline 9 & UCLND & $2 \mathrm{Y}$. & $10 \mathrm{Y}$. & Figure 19 \\
\hline
\end{tabular}

"Technique demonstration case; ${ }^{* *}$ Single Stage, cleft lip and palate surgery; $M=$ Months; $\mathrm{Y}=$ Years.

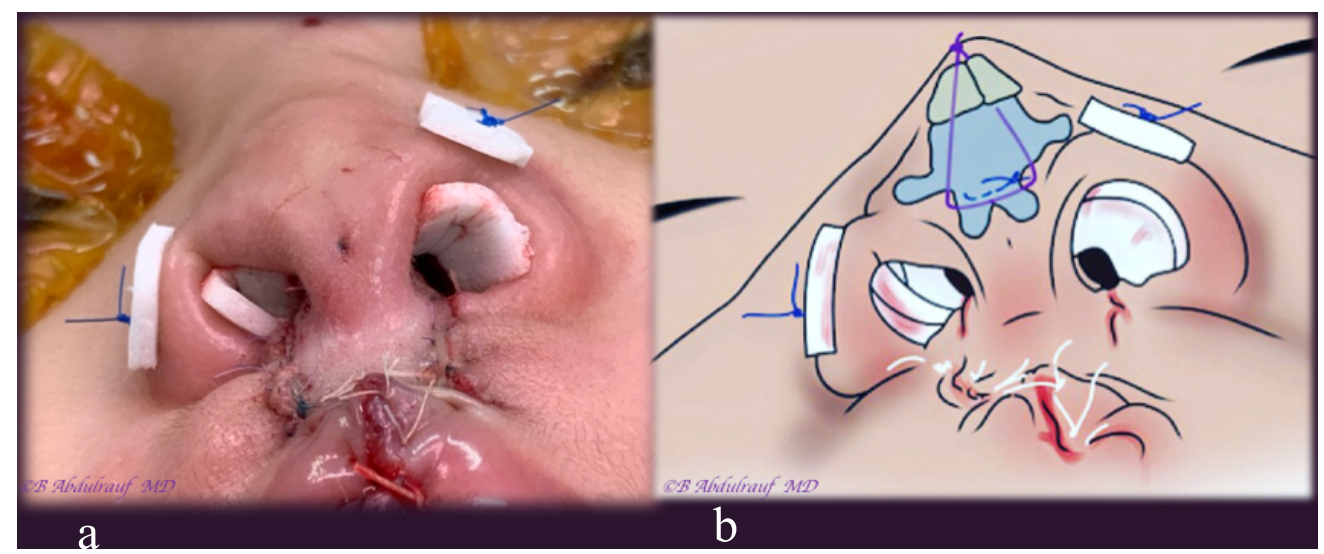

Figure 6: Case 1 basal view at completion, bolster sutures are used occasionally to reduce minor hematomas and fibrosis (a). Author's view of the underlying repair (b).

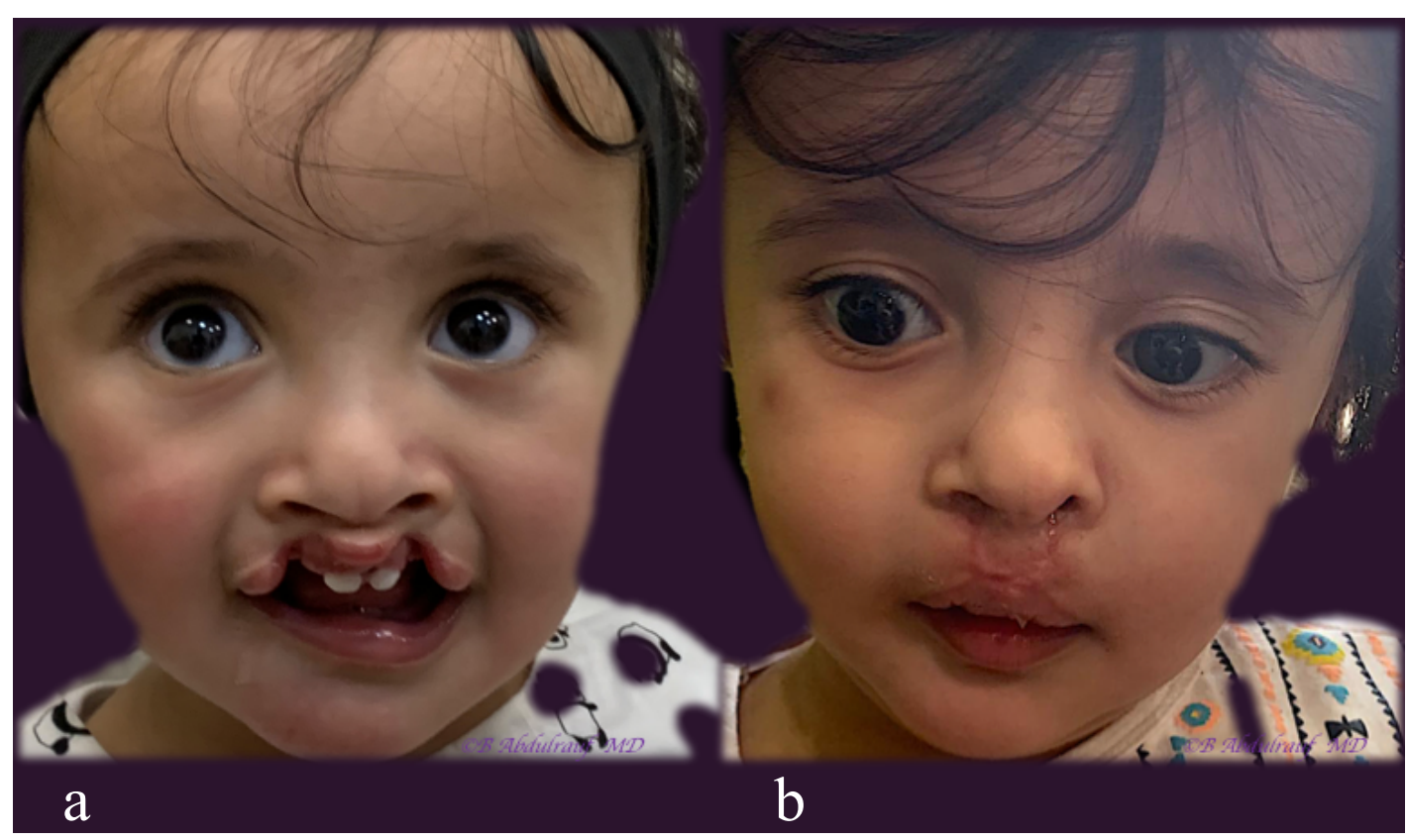

Figure 7: Case 1, was used for technique demonstration as an example of BCLND, operated at age of 14 months (a). 3 months follow up, we intentionally preserve the philtral width at primary surgery instead of banking or discarding, this would be extremely useful in case of a future Rhinoplasty otherwise the lip can be revised to optimal philtral width at teenage (b). 


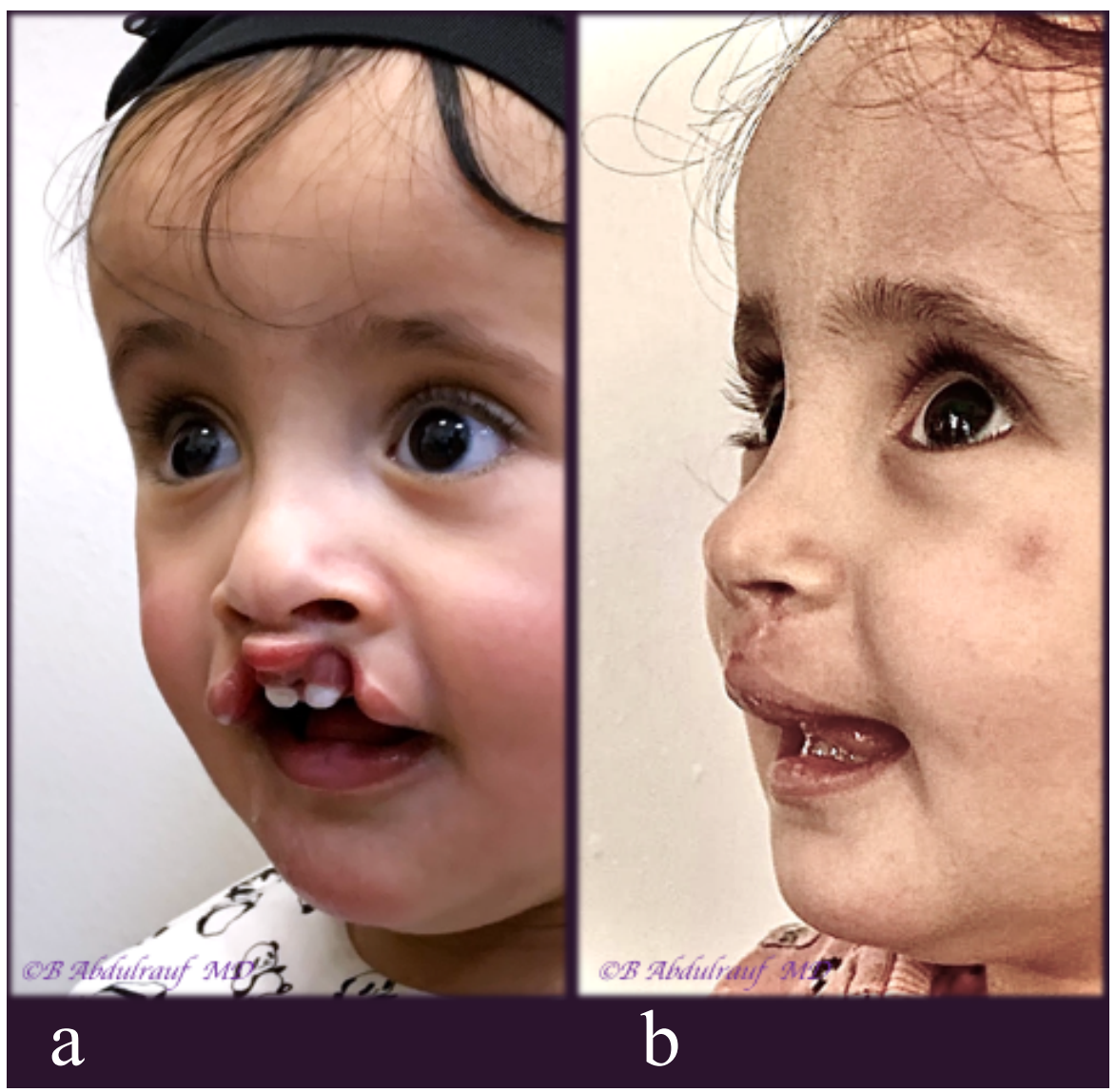

Figure 8: Case 1 cont'd. Oblique view (a) postoperative at 3 months, Columella has been lengthened, nasal tip is defined and repositioned.

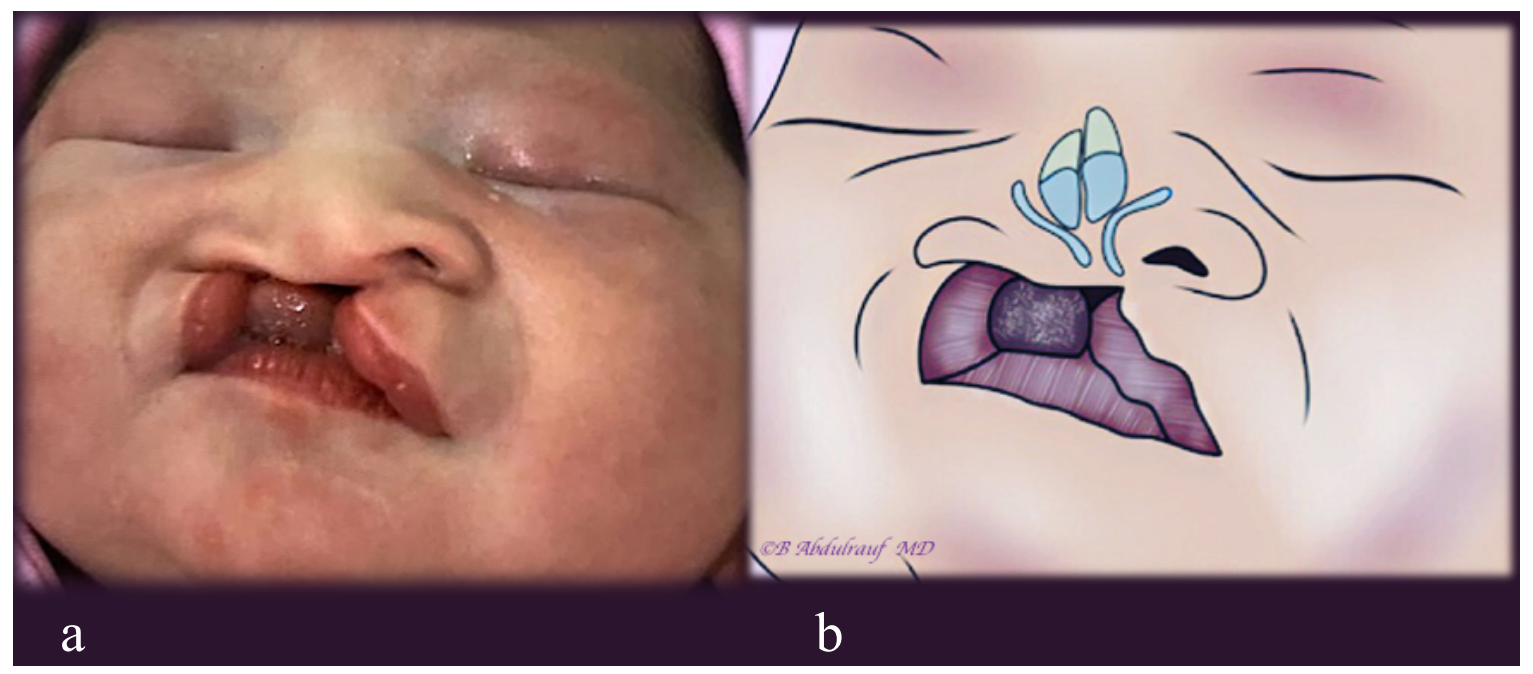

Figure 9: Case 2: As a newborn with a severe UCLND, significant alveolar gap, the caudal septal and columellar deformity is quite pronounced (a). Expected underlying cartilaginous deformity on cleft side and significant asymmetry due to the "tilted Tripod" theory (b).

\section{Discussion}

\section{The lip repair}

Selection of the technique for Cleft lip repair largely depends on whom one was influenced, in terms of mentor(s).
It is impossible to discuss the Nasal correction aspect in clefts without including primary approaches to the cleft lip, which is also quite diversely executed by surgeons.

It was interesting to learn from a mentor like Dr. Hugh Thompson, this seems to be the norm, there is nothing wrong 


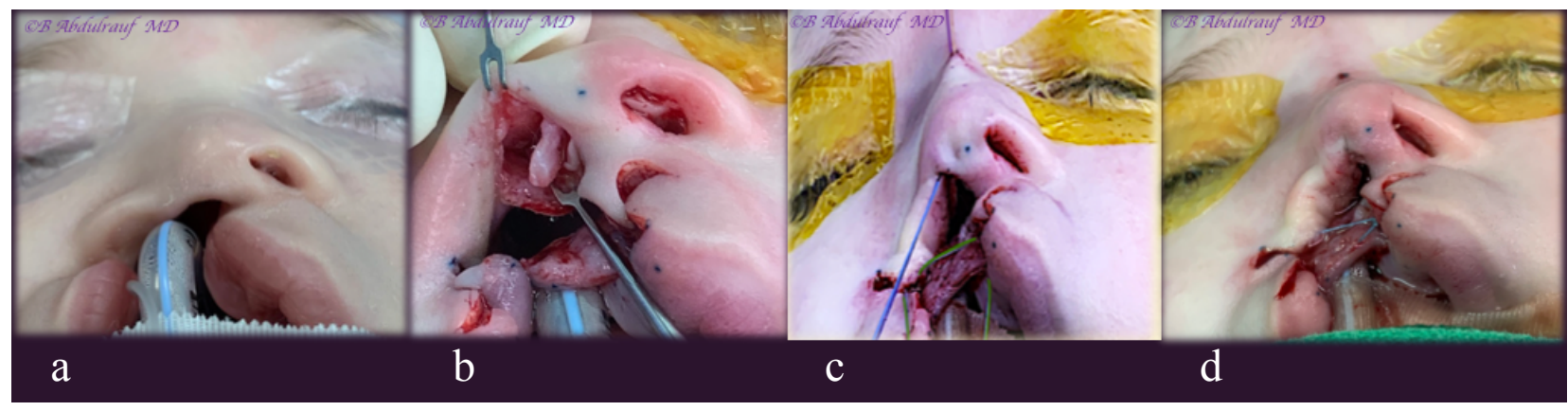

Figure 10: Case 2: Intraoperative basal view (a). Lateral crus dissection, skeletonizing and steal maneuver for medial crus lengthening (b). The 3 key sutures: A Cinch ethibond suture holding alar fibrofatty tissue to premaxillary periosteum; Trans-domal PDS suture; and the Cantilever lifting vicryl thread, seen coming out at the radix (c). All 3 sutures have been tied beginning with the Cinch, followed by Trans-domal, and last the Cantilever thread. The nose has been fully reconstructed prior to and independent to the lip repair (d).

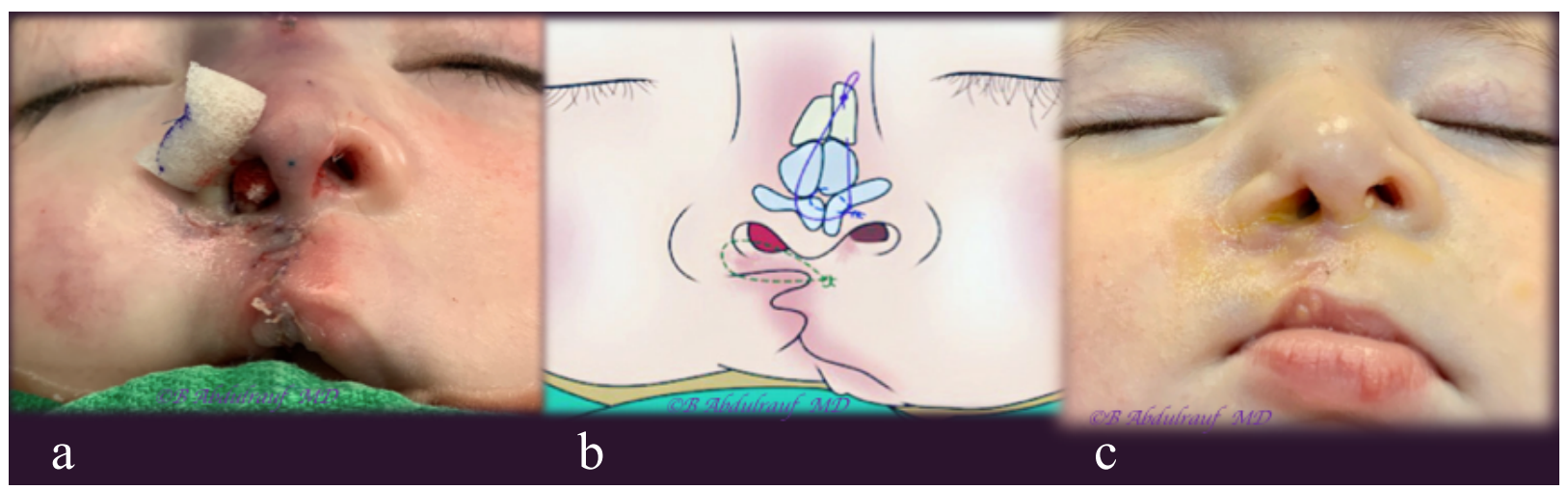

Figure 11: Case 2 cont'd., a single bolster suture used at alar rim (usually removed in 48 hours), the lip has been repaired, the fact it was mildly deficient in height was recognized (a). Author's simulation of Nasal reconstruction and the 3 key sutures (b). One week postoperatively (c) (medical honey-based ointment seen on the lip).

to do a hybrid kind of an operation for cleft lip; and nobody would object to an expert of being innovative [6].

Our first mentor Dr. Miroslaw Stranc who extensively worked on lip function studies [7], a strong believer in the rotation advancement technique and often expressed, "if you end up by doing clefts your mistakes are going to grow with you!".

Later on, as the first fellow with Dr. D. Fisher, been influenced with his concept of anatomic subunit principle which was still undergoing a prospective study [8]. Then close to 20-years of doing cleft work, we found ourselves have adopted few modifications here and there as well. If we decide to do rotation advancement, then usually use Noordhoff's modifications $[9,10]$.

Regarding Bilateral cleft, we tend to use few concepts from both Millard and also Mulliken techniques but without narrowing the philtrum to near normal dimension at the primary surgery. We do not agree on discarding skin in infancy.

\section{Historic review of approaches to the nose}

It is interesting, not too long-ago surgeons began giving more serious consideration to the early cleft nose approach [11].

Historically, different suturing techniques have been sug- gested and described to secure the surgically dissected cartilages and freed at dome area, as well cephalically [12].

To secure the repositioned lower lateral cartilages, mattress sutures have been used by Tajima in 1977, holding the lower laterals to the Triangular cartilages, as part of their described approach to secondary correction of the cleft nose [13]. Kernahan, et al. presented their results with same technique of Tajima [14], who then presented their long-term results of the original approach with some additions [15].

McComb used mattress sutures to reposition the nasal cartilages after undermining nasal skin, securing them externally as bolster sutures. Those mattress sutures depend on dermal resistance to maintain their traction, and need to be removed approximately in 5 days. They demonstrated the technique initially in the UCLND [16] and later presented their long term follow ups in both Unilateral and Bilateral clefts $[17,18]$.

Stenstrom, beside the rim incisions, added a small external incision on the dorsum in order to lift the affected alar cartilages and securing them to the septal cartilage with non-absorbable sutures [19].

\section{The current literature on cleft Nasal deformity}

Major authorities on Cleft care and craft of the current era indicated: The nasal deformity is the most likely stigma that remains clearly visible despite vigorous and repeated at- 


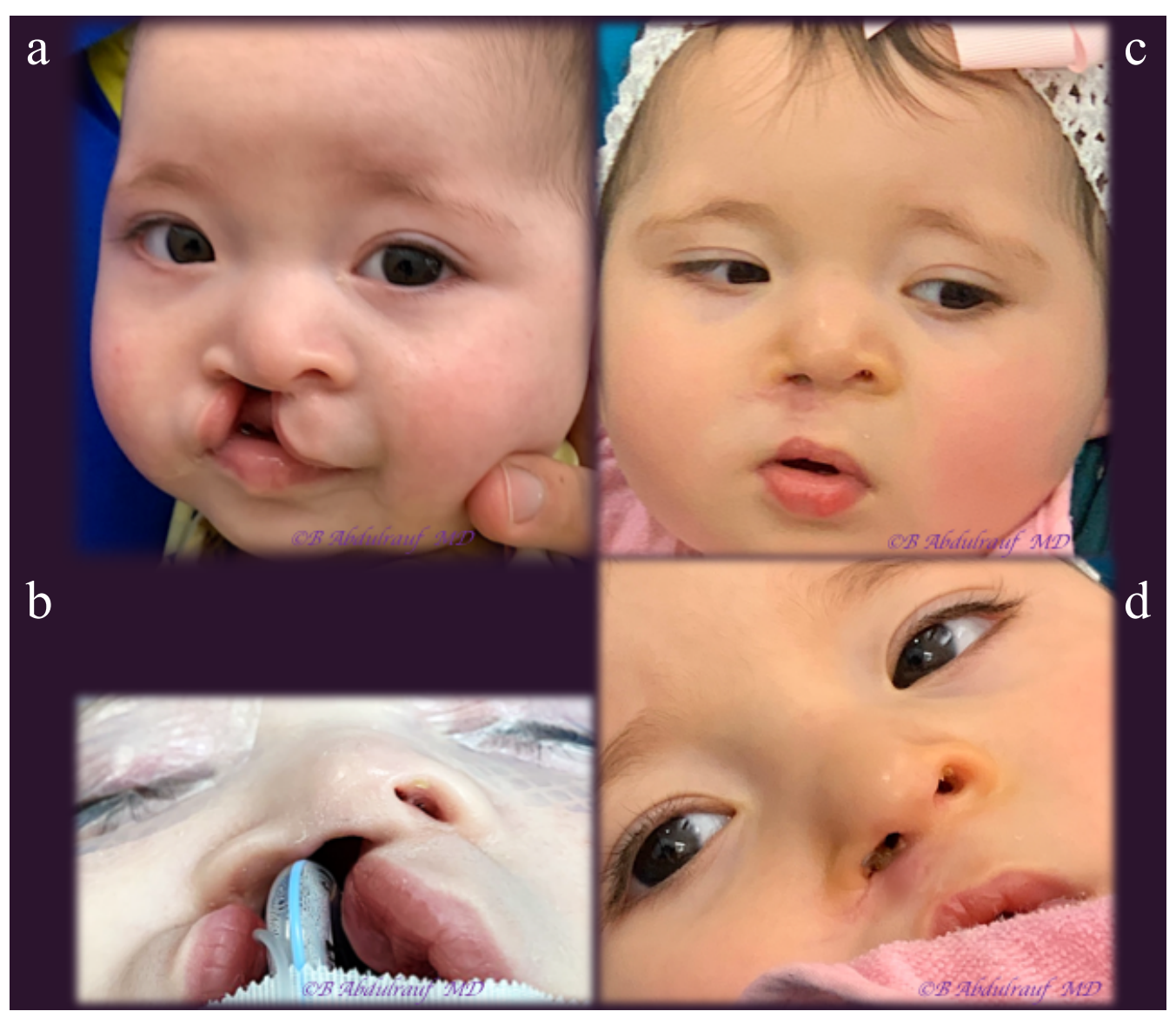

Figure 12: Case 2: Used as an example for technique demonstration in UCLND at 4 months $(a, c)$. Five months postoperative follow up pictures, the nose is maintaining its reconstructed shape. Lip outcome was somewhat expected (b, d) There is some scar hypertrophy at nasal sill.

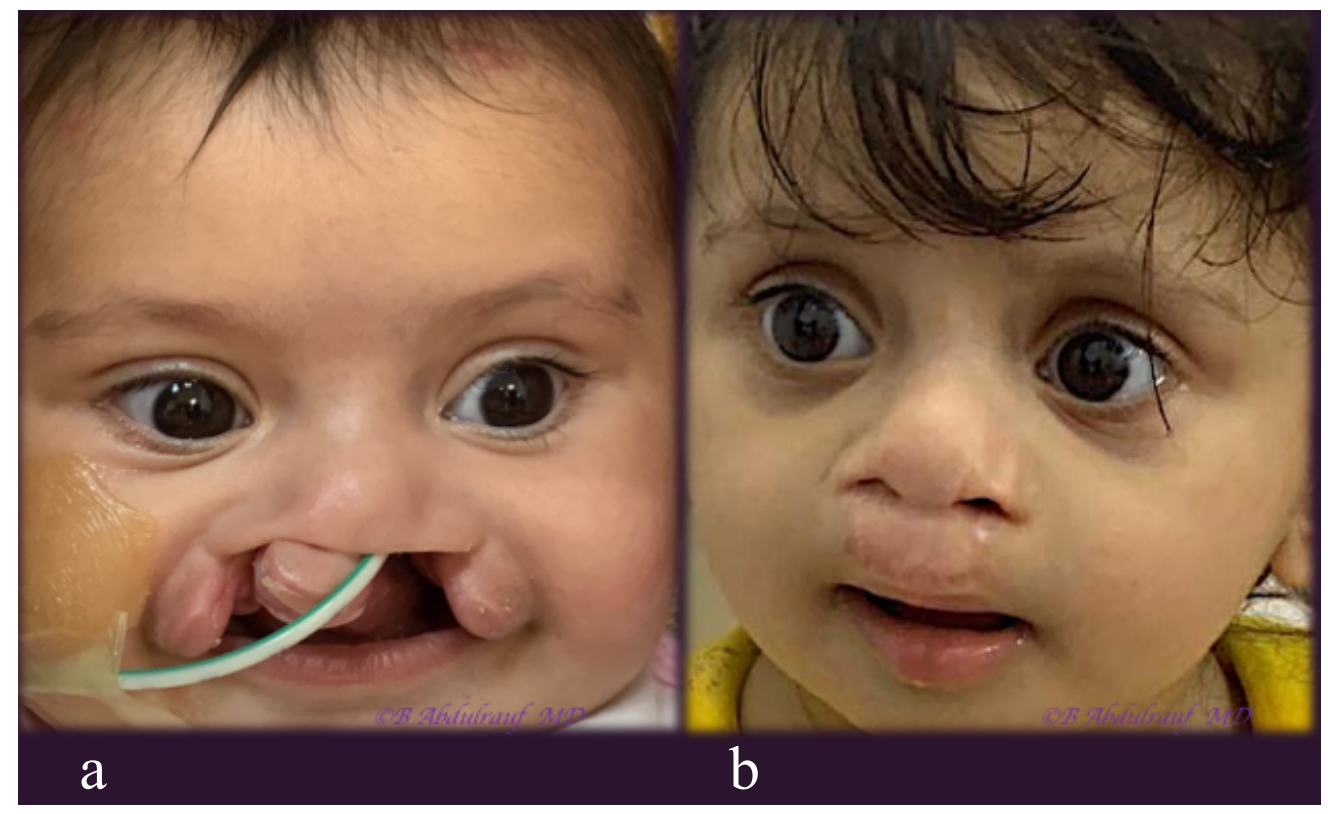

Figure 13: Case 3: BCLND, severe and significant asymmetry, operated at 6 months (a) One year postoperative follow up is shown (b). Although we use some maneuvers of Mulliken's methods but we save most of the philtra skin at this age. 


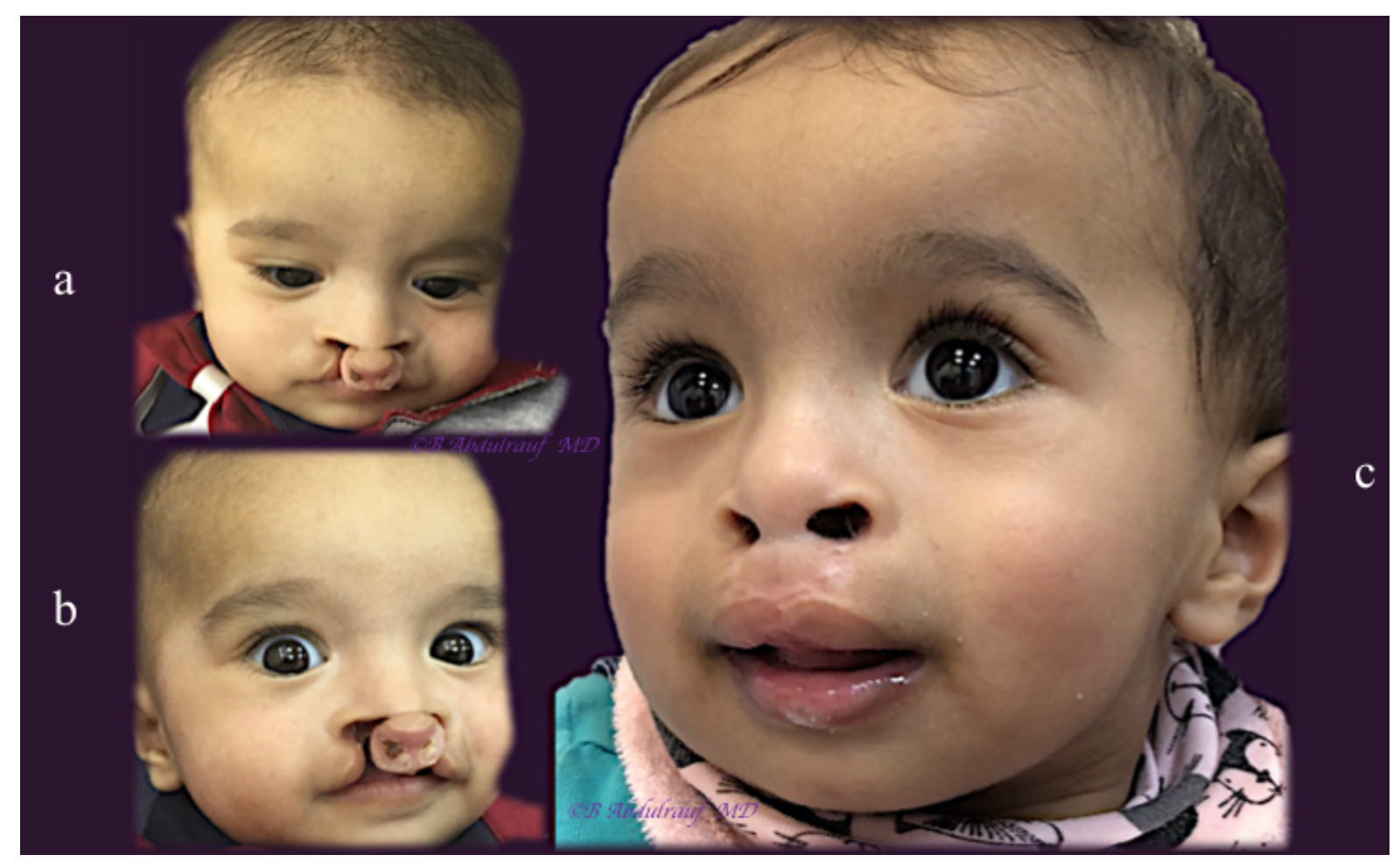

Figure 14: Case 4: BCLND, like many other cases the columella here has not formed, it is quite noticeable in these images, patient operated at age of 8 months ( $a, b)$ Follow up picture 2-years postoperatively (b). As usual, we do not discard any philtra skin at this age. Although the original anomaly is severe but also quite symmetric, the long term aesthetic outcome in this case can be predicted to be very good. This is contrary to older beliefs on BCLND.

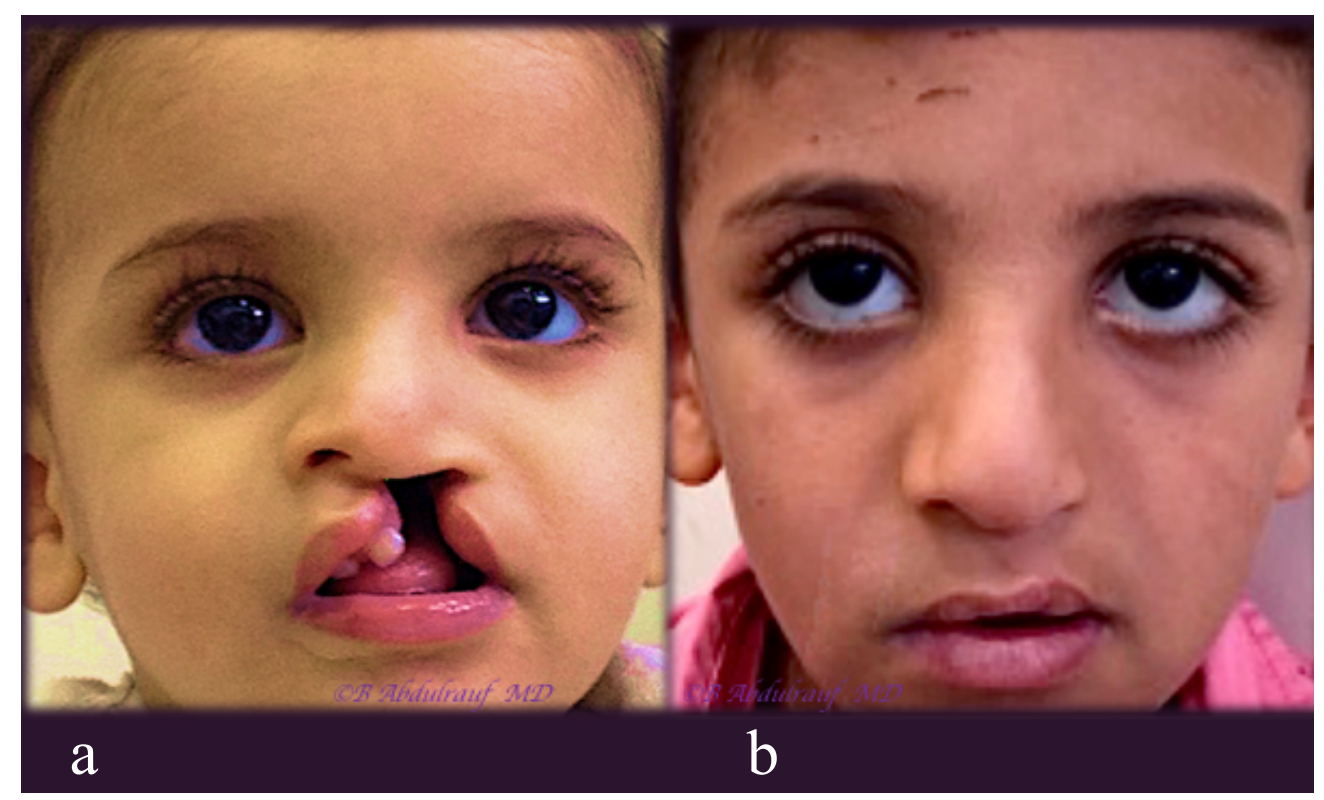

Figure 15: Case 5: UCLND, this child was operated at age of 18 months as single stage for cleft palate and UCLND (a) Follow up 6-years postoperatively (b).

tempts at correction [4]; Due to the several factors involved in the nasal cleft patho-anatomy, the deformity is not in fact amenable to correction at the index operation [2]. It is easier to obtain results in symmetric Bilateral cleft lip compared to Unilateral, and the latter requires more revisions [4]; Cleft lip repair is primarily a nasal surgery [1].
Out of those statements, one could simply extrapolate 3 simple conclusions:

- The diagnosis of "Cleft lip case" is probably an underestimating and inappropriately deficient, lacks the major challenging aspect of the anomaly, namely nasal deformity.

- Nasal correction aspect must take priority at the prima- 


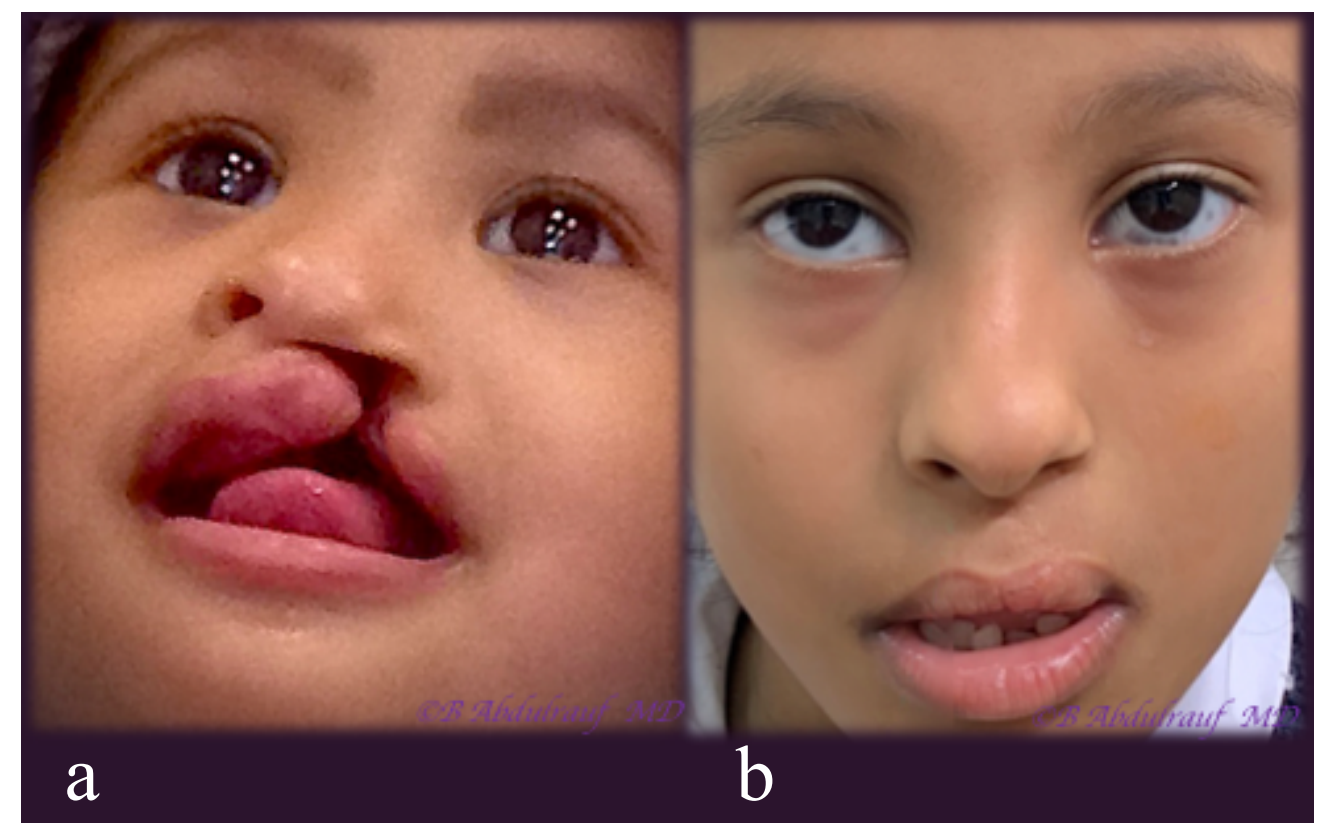

Figure 16: Case 6: UCLND, operated at age of 11 months (a). Follow up picture 6 years post -surgery (b).

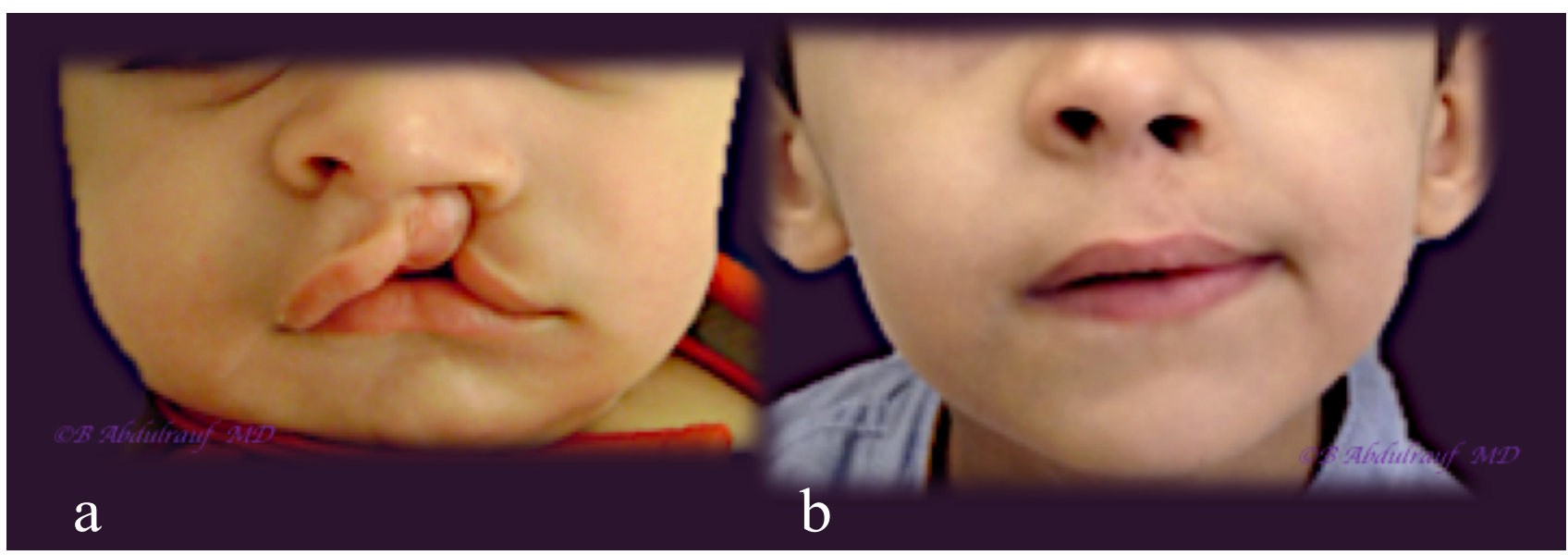

Figure 17: Case 7: UCLND, operated at 5 months (a) Follow up picture 10 years post-surgery (b).

ry surgery since it is less forgiving on the long term, due to the underlying cartilaginous deformity and soft tissue memory.

- The old message or classic teaching that successful treatment of the Bilateral complete cleft and palate can be the most difficult task $[20,21]$, with all due respect is actually not true and a misconception; the challenge is not about reconstructing a double defect. The tilted Tripod theory applicable specifically to Unilateral clefts, makes them far more challenging from the nasal point view and on the long term [5].

\section{Our method of nasal suspension}

The procedure involves wide undermining and complete freeing of involved lower laterals, in addition to the alar bases; an internal long-lasting mattress cable suture is used and been secured to a much stable base, periosteum of the nasion, the orientation of this suture varies depending whether the cleft being unilateral or bilateral. This is beside alar cartilages recruiting, domal equalization and cinch sutures. All previously reported techniques depended on securing lower lateral cartilages to other mobile structures, like triangular cartilages or the skin. Our way of Cinch sutures is done differently as well, they have been secured to the premaxillary periosteum.

NAM or other presurgical corrective manipulations as well as post-surgical nostril silicone splints work on the principles of sculpturing or supporting the nose [22]. Those can be extremely useful devices, when started early enough. Compliance, repeated efforts of teaching parents has been an issue in our practice, due to the long distances of many of these patients. Besides, properly trained craniofacial orthodontists are not yet adequately available in most of the peripheral provinces.

Although we have been applying the subunit principle technique to many of the Unilateral cases, when it came to 


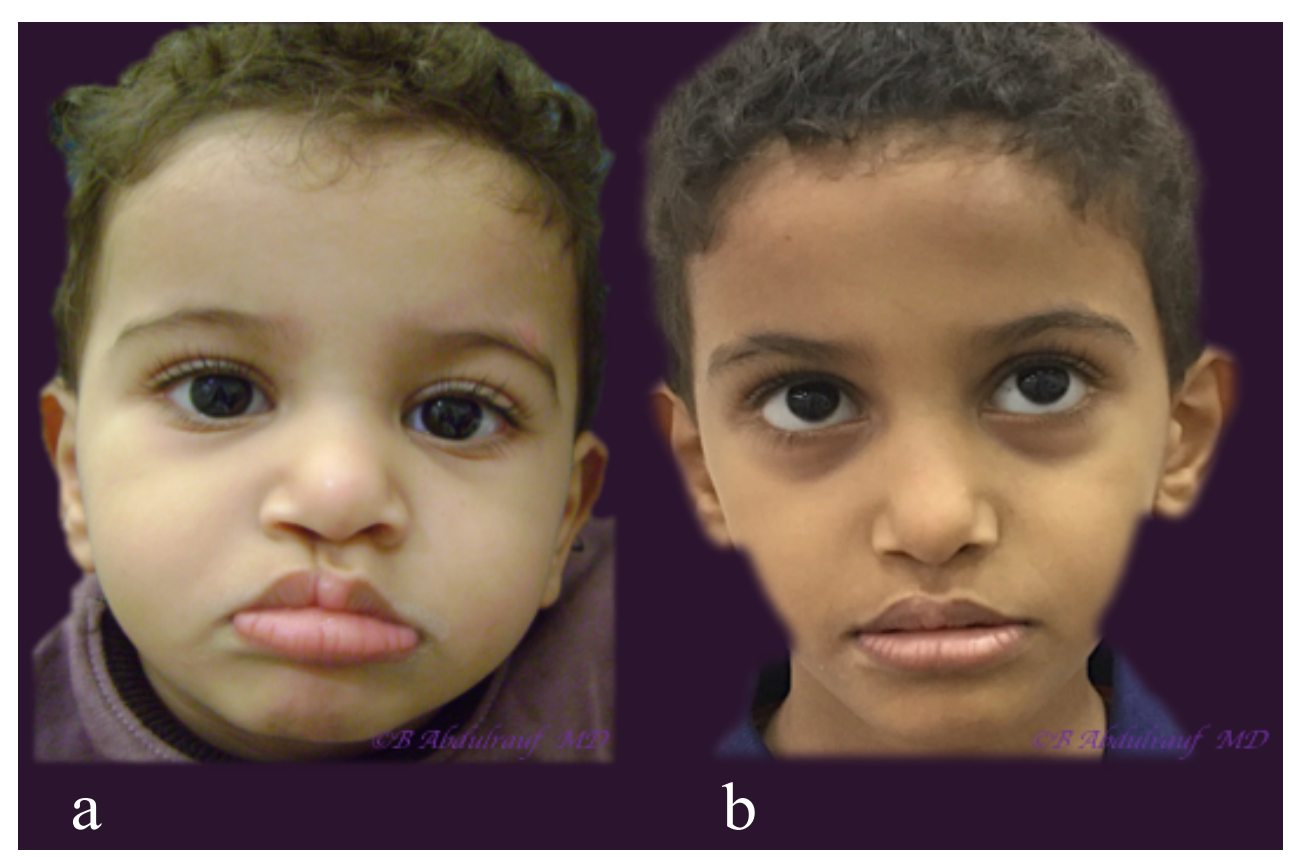

Figure 18: Case 8: UCLND, "form fruste" type, was operated at age of 2-years (a) Follow up picture 10-years post-surgery (b).

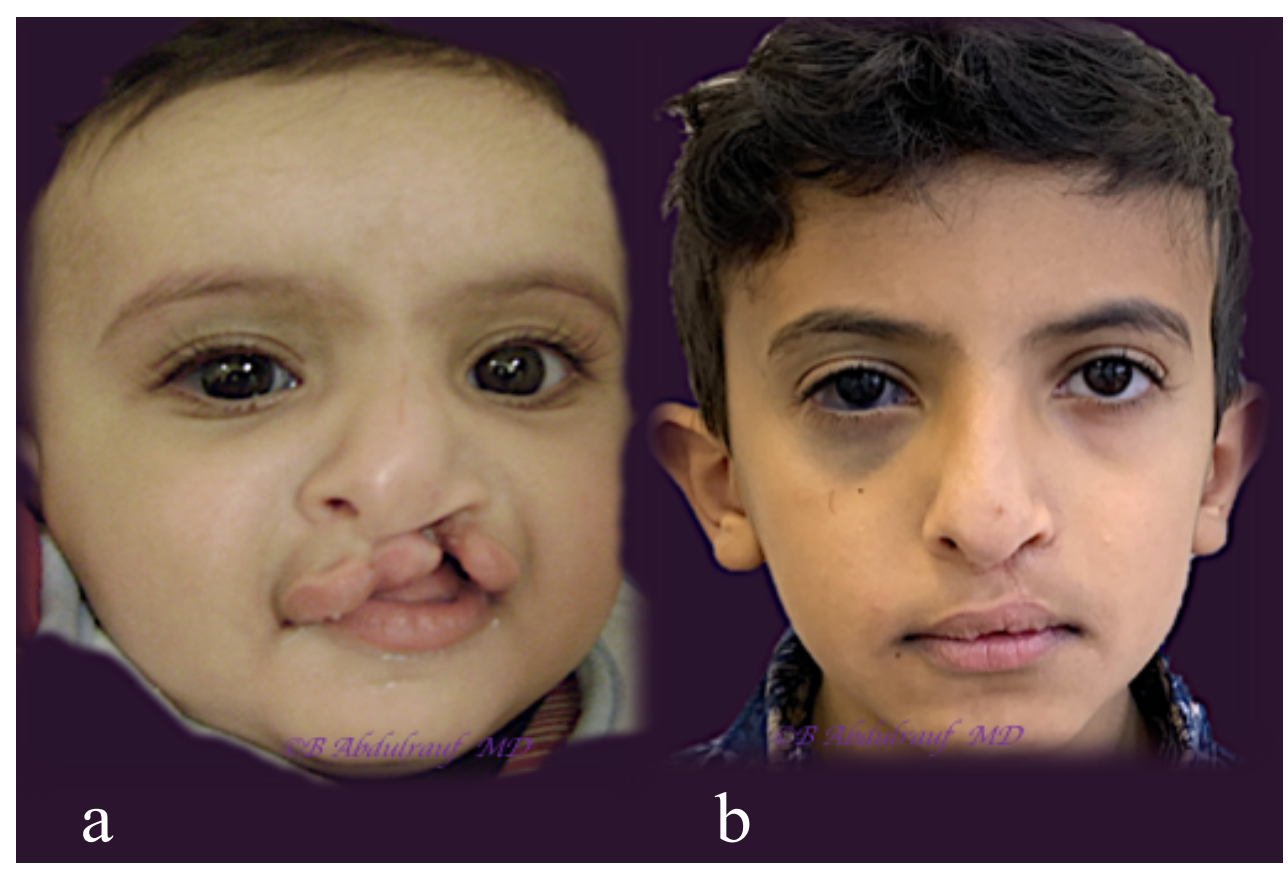

Figure 19: Case 9: UCLND, was operated at age 8 months (a) Follow up picture 10-years post-surgery, lip has mild shortening which might require revision (b) Patient also has nevus of Ota, right orbit.

nasal correction we initially had the tendency to use McComb's technique of external mattress sutures. The most unfavorable part of this was the fact, it depends barely on the skin to hold the freed cartilages. Second, those bolsters will need to be removed very soon.

The surgical technique described here, repositions the cartilages and soft tissues in a desired and over corrected position after they have been completely freed, and holds that position internally to a fixed base, the periosteum. (Figure 4c, Figure 6b, Figure 5b, Figure 5d, Figure 11b).
The choice of material to be used for "the loop suture" was based on a material that would absorb in reasonable time and with secure knot quality. PDS was initially attempted however the knot would not "slide" away from the radix mini incision. This potentially could have led to stitch granulomas. We found vicryl or ploysorb suture worked better from this aspect, we were able to slide and place the knot further caudal over the nasal bones in relation to the mini incision. This could have been related to the mild elastic property of these sutures. We avoided the use of permanent material for 


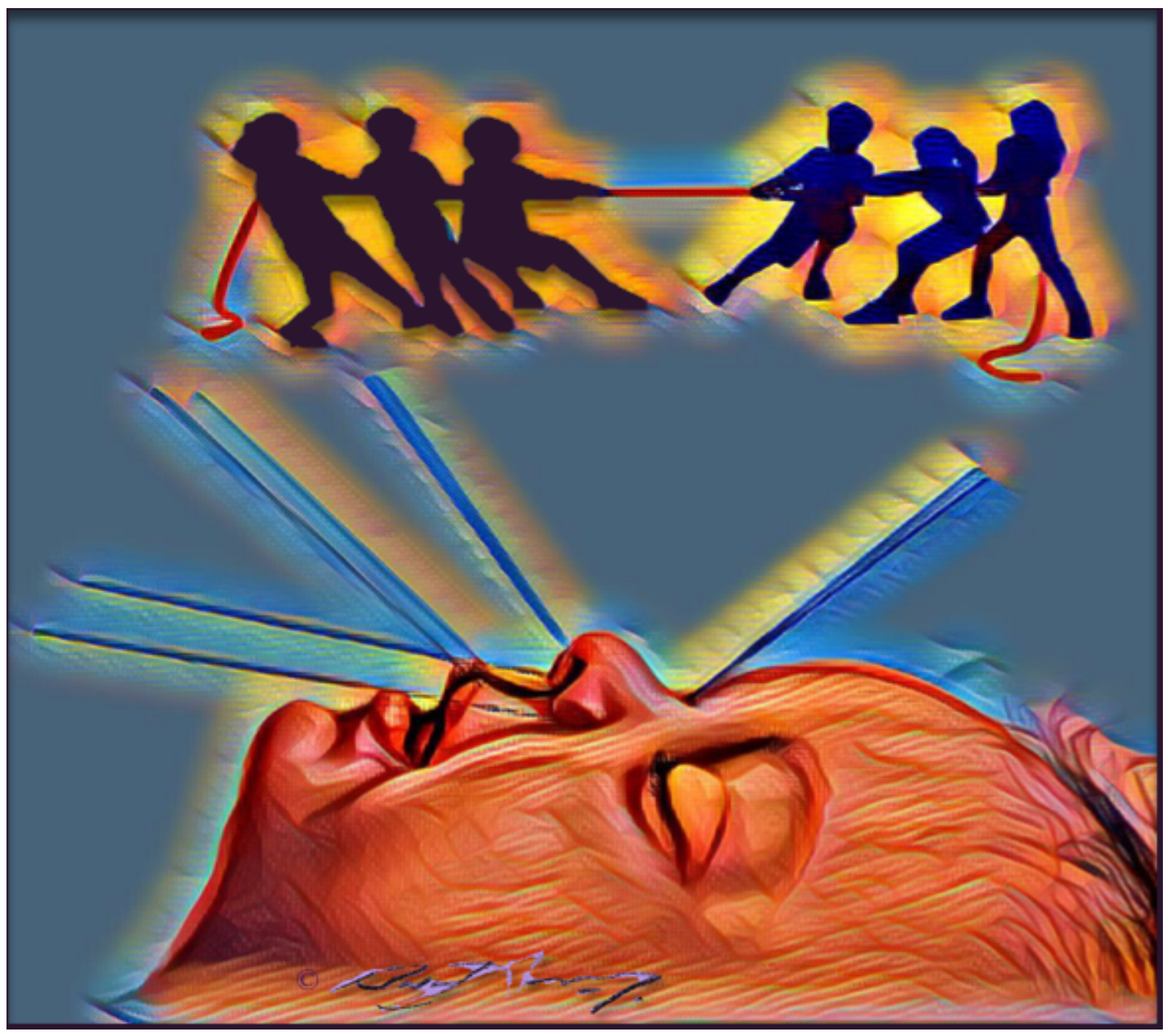

Figure 20: The Nasal and Lip units share borders, when there is cleft it tends to act as a malformation. Simultaneous repair to both whether in childhood or secondarily means attempting to recruit tissues in opposite vectors. Tissues will resist due to their inherent memory and compromise of results on either side is probable. Hence the analogy "Tug of War" phenomenon.

suspension due to risk of being apparent under dorsal skin or possible restraining effect on nasal growth longitudinally.

Early in our practice we were exclusively trained in open tip Rhinoplasty. However, when dealing with infants, preschool children and teenage logically one should be aiming for interceptive procedures.

Almost all these children one day are going consider definitive Rhinoplasty with proper open technique. Presence of columellar scars and fibrosis otherwise from an early stage of life, would hinder the definitive long-term Rhinoplasty. Therefore, we had to acquire closed technical skills. With a learning curve, it is Not impossible to reshape the nose with entirely closed techniques $[4,23]$. The procedure presented here barely utilizes infra cartilaginous incisions and tiny 2 needle induced openings on the skin.

We have not been considering specific septal work at the primary surgery as well, this is due to the concern with possible future effect on growth centers (which in part reflects influence of well-known mentors).

More importantly we are already centralizing the nose with crural and tip work and hence the septum in the cases of UCLND. We believe the Septum and entire nose would follow each other far better at this young age, this can be observed with the on table results and with the long term outcomes. Having said that, it is up to the discretion of each surgeon to do what works better in their hands.

\section{Opposite vectors, "Tug of War phenomenon"}

The fact primary correction requires simultaneous repair of both lip, and the nose, a question arises: Will one of them need to be compromised?!

Many surgeons would have good lip results but less than average noses, and vice versa. This is also why secondary" cleft rhinoplasty" in adults is not being combined with lip revision. The Nasal and Lip units share borders and when there is clefting, it acts very much like a malformation.

Parameters as presurgical orthopedic manipulation, strict collaborative programs and compliance, play major role in outcomes of cleft surgeons $[2,4,22]$. The cleft nose deformity correction whether primary or secondary has been a daunting task to so many cleft surgeons to the extent one author very humbly admitted, it has been impossible in their hands to correct this deformity [24].

In fact, very few "Aesthetic Rhinoplasty" surgeons would 
Citation: Abdulrauf BMI (2020) An Ultimate Method for Cleft Nasal Deformity Correction at Primary Lip Surgery: Innovative Concepts and Review. Archives Oral Maxillofac Surg 3(1):36-49

like to deal with cleft noses. When an adult patient with congenital anomaly consults a Rhinoplasty surgeon, they would have very high expectations, simply because they consulted a cosmetic surgeon. The surgeon in turn knows, they would not be able to reach a result anywhere close to their average cosmetic rhinoplasties [2,26].

When one is working into opposite vectors, it is difficult to reach optimum harmony, a compromise on either side is expected. Tissue's do their best to return where they used to be, while combating with the fibrosis created by the surgical intervention. Hence our analogy, "Tug of war" which we believe best explains the situation with primary or secondary corrections to the nose or to the lip (Figure 20).

The Cantilever concept in the nose is well known, originally of Converse and Millard, when they described a Cantilever bone graft secured to the radix in reconstructing the dorsum [25].

The cleft lip nasal deformity has a unique pathology [2]. The cartilages and skin tend to maintain their memory, and it comes mostly under domain of the Reconstructive surgeon, who are used to face challenges and are expected to be creative $[26,27]$.

None of the patients shown in this article at least had preoperative NAM or orthopedic manipulations, besides all of them had a delayed primary surgery, due to logistic issues.

Disadvantages to our method include: The need for a learning curve, potential risk of stich granuloma or potential risk of abnormal scars at the 2 sites of needle induced openings on the radix and nasal infra-tip.

\section{Conclusion}

In current era, Surgeon's satisfaction with BCLND surgery is higher compared to UCLND, due to the newer techniques enabling to build a less scarred columella meanwhile with the advantage of a preexistent relative nasal symmetry.

Nasal correction aspect is the dominant part of surgery in cleft lip, and it is less forgiving compared to the lip surgery relatively speaking.

Cleft surgery should only be done by sub specialized surgeons.

The cleft Nasal-Lip surgery tends to be more challenging with time, because our earlier minor misjudgments tend to become more pronounced with several years of follow up. New philosophies and approaches to the primary surgery will always be evolving.

The Nasal suspension method that lifts the whole nasal collapsing "Tent" and holds it into a fixed base (the nasion), is a new and solid concept, it promises to be an ultimate corrective approach to the Nasal "patho-anatomy" in children with cleft Nasal-Lip deformity.

\section{Acknowledgment}

The Illustrations and drawings are work of the (Author) himself.

\section{References}

1. Mulliken JB (2001) Primary repair of bilateral complete cleft lip and nasal deformity. Plast Reconstr Surg 108: 181-194.

2. Fisher MD, Fisher DM, Marcus JR (2014) Correction of the cleft nasal deformity: From infancy to maturity. Clin Plast Surg 41: 283-299.

3. Kernahan DA, Bauer BS, Harris GD (1980) Experience with the Tajima procedure in primary and secondary repair in unilateral cleft-lip nasal deformity. Plast Reconstr Surg 66: 46-53.

4. Mulliken J (2000) Repair of bilateral complete cleft lip and nasal deformity-state of the art. Cleft Palate Craniofacial J 37: 342-347.

5. Hogan VM, Converse JM (1971) Secondary deformities of unilateral cleft lip and nose. In: Grabb WC. Rosentein SE, Bzoch KR (edn), Cleft lip and palate. Little Brown and co, Boston 245.

6. Thomson HG (1995) Unilateral cleft lip repair. Operative techniques in Plastic Reconstructive Surgery 2: 175-181.

7. Fogel ML, Stranc MF (1984) Lip function: A study of normal lip parameters. Br J Plast Surg 37: 542-549.

8. Fisher D (2005) Unilateral cleft lip repair: An Anatomical subunit sub unit approximation technique. Plast Reconstr Surg 116: 61-71.

9. Millard DR (1964) Refinements in rotation advancement cleft lip technique. Plast Reconstr Surg 33: 26-38.

10. Noordhoff MS (1984) Reconstruction of vermilion in unilateral and bilateral cleft lips. Plast Reconstr Surg 73: 52-61.

11. Millard DR Jr (1982) Earlier correction of the unilateral cleft lip nose. Plast Reconstr Surg 70: 64-73.

12. Converse JM, et al. (1977) Secondary deformities of the cleft lip, cleft lip and nose, and cleft palate. In: Converse JM, McCarthy JG (edn), Reconstructive Plastic Surgery, Philadelphia 4: 2165.

13. Tajima S, Masaru M (1977) Reverse-U incision for secondary repair of cleft lip nose. Plast Reconstr Surg 60: 256-261.

14. Kernahan DA, Bauer BS, Harris GD (1980) Experience with the Tajima procedure in primary and secondary repair in unilateral cleft-lip nasal deformity. Plast Reconstr Surg 66: 46-53.

15. Tajima S (1990) Follow up results of the unilateral primary cleft lip operation with special reference to primary nasal correction by the author's method. Facial Plast Surg 7: 97-104.

16. McComb H (1975) Treatment of the unilateral cleft lip nose. Plast Recon Surg 55: 596-601.

17. McComb HK, Coghlan BA (1996) Primary repair of the unilateral cleft lip nose: Completion of a longitudinal study. Cleft palate craniofacial J 33: 23-30.

18. McComb H (1986) Primary repair of the bilateral cleft nose: $10-$ year review. Plast Reconstr Surg 77: 701-716.

19. Stenstrom SJ (1977) Correction of cleft lip nasal deformity. A refinement of an older method. Plast Reconstr Surg 59: 675-679.

20. Manchester WM (1965) The repair of bilateral cleft lip and palate. BJPS 52: 878-882.

21. Brown JB, McDowell F, Byars LT (1974) Double clefts of the lip. Surg. Gynaecolog Obstet 85: 20.

22. Grayson BH, Cutting CB (2001) Presurgical naso-alveolar orthopedic molding in primary correction of the nose. Lip and alveolus of infants born with unilateral and bilateral clefts. Cleft palate Craniofac J: 193-198. 
Citation: Abdulrauf BMI (2020) An Ultimate Method for Cleft Nasal Deformity Correction at Primary Lip Surgery: Innovative Concepts and Review. Archives Oral Maxillofac Surg 3(1):36-49

23. Tibbets JB (1994) Shaping and positioning the nasal tip without structural disruption: A new systematic approach. Plast Reconstr Surg 94: 61-77.

24. Randall P (1992) History of cleft lip nasal repair. Cleft Palate Craniofac J 29: 527-530.

25. Abdulrauf B (2020) The reconstructive plastic surgeon vs. the aesthetic plastic surgeon: Perspective 2020. Int J Surg Clin Prac 2: 1-2.

26. Converse JM, (1977) Reconstructive plastic surgery. ( $2^{\text {nd }}$ edn), Philadelphia.

27. Rohrich RJ, Sullivan D (2011) So do you want to be like leonardo da vinci or michelangelo? Which one are you? Plast Reconstr Surg 128: 1309-1311.

DOI: $10.36959 / 379 / 353$ 